\title{
Chronic Morphine Treatment Modulates the Extracellular Levels of Endogenous Enkephalins in Rat Brain Structures Involved in Opiate Dependence: A Microdialysis Study
}

\author{
Magdalena Mas Nieto, ${ }^{1}$ Jodie Wilson, ${ }^{1}$ Annie Cupo, ${ }^{2}$ Bernard P. Roques, ${ }^{1}$ and Florence Noble \\ ${ }^{1}$ Département de Pharmacochimie Moléculaire et Structurale Institut National de la Santé et de la Recherche Médicale \\ U266, Centre National de la Recherche Scientifique Unité Mixte de Recherche 8600, Université René Descartes, Unité de \\ Formation et de Recherche des Sciences Pharmaceutiques et Biologiques, 75270 Paris Cedex 06, France, and 2Institut \\ de Pharmacologie Moléculaire et Cellulaire, Centre National de la Recherche Scientifique Unité Propre de Recherche 411, \\ Université de Nice-Sophia-Antipolis, 0650 Valbonne, France
}

\begin{abstract}
The endogenous opioid system is often assumed to play a role in vulnerability to drug abuse. However, controversial results have been reported regarding the levels of enkephalins or preproenkephalin in neurons of rodent brains after opiate administration. The present study was performed to determine the extracellular levels of enkephalins and its physiological antagonist cholecystokinin (CCK), using in vivo microdialysis in freely moving rats after morphine-induced physical dependence or positive place conditioning. A large increase (340\%) of Metenkephalin was observed in the periaqueductal gray matter, a structure involved in morphine withdrawal syndrome, in morphine-dependent rats. No change in CCK immunoreactivity occurred in these conditions. Moreover, using the conditioning
\end{abstract}

place preference paradigm, we observed for the first time opposite changes of enkephalin outflow in the nucleus accumbens (NAc). Thus, an increase in enkephalin levels was observed in rats placed in the drug-associated compartment and a decrease in the saline-paired side. These changes in opioid peptides in the NAc may reflect an "emotional state" of the animals in relation to the expectation of drug reward (reinforcing effects of morphine). Moreover, the lack of regulation in CCK outflow suggests that CCK-opioid interactions in morphine dependence involve probably post-receptor events.

Key words: enkephalin; cholecystokinin; microdialysis; reward; morphine dependence; hippocampus; nucleus accumbens; periaqueductal gray matter
Several studies have reported that the endogenous opioid system could contribute to the acute and long-term effects of opiate and other addictive drugs (Herz, 1997) (for review, see Van Ree et al., 1999), in agreement with the reinforcing effects induced by electrical stimulation of enkephalin-rich regions of the brain (for review, see Kornetsky and Bain, 1982). The central role of the opioid system in drug-addictive processes is supported by the ability of opioid antagonists, such as naltrexone or naloxone, to reduce the consumption of heroin, cocaine, and ethanol in experimental animals (Ettenberg et al., 1982; Samson and Doyle, 1985; Kornet et al., 1991; Negus et al., 1993). Moreover, recent findings in alcohol- and cocaine-dependent patients showed that craving and relapse are attenuated after treatment with the opioid antagonist naltrexone (for review, see O’Brien et al., 1996; O’Malley, 1996; Oslin et al., 1999; Schmitz et al., 2001).

Data in the literature regarding opioid-induced regulation of the brain enkephalin system are controversial. Thus, increases or decreases in enkephalin immunoreactivity were reported to occur in brain tissues after chronic treatment with morphine, whereas in other studies, no change was observed (Van Bockstaele et al.,

\footnotetext{
Received July 30, 2001; revised Nov. 2, 2001; accepted Nov. 2, 2001

This work has been supported by European Union Biomed II Programme BMH4 CT98 2267. We gratefully acknowledge C. Dupuis for expert manuscript drafting and C. Canestrelli for the animal care.

Correspondence should be addressed to Dr. Florence Noble, Université René Descartes, Unité de Formation et de Recherche des Sciences Pharmaceutiques et Biologiques, 4 Avenue de l'Observatoire, 75270 Paris Cedex 06, France. E-mail: noble@pharmacie.univ-paris5.fr.

Copyright (C) 2002 Society for Neuroscience $\quad 0270-6474 / 02 / 221034-08 \$ 15.00 / 0$
}

2000). These differences are very likely attributable to the following: (1) the various experimental protocols used in chronic opioid treatment and the regioselectivity of the effects (Tejwani and Rattan, 1997); and (2) the use of different techniques to measure the enkephalin levels, such as autoradiography (Gerrits et al., 1999), in situ hybridization (Lightman and Young, 1987; Tjon et al., 1997), or peptide extraction from tissues (Tejwani and Rattan, 1997).

Addiction could be considered as a defective behavioral state issuing from a defect in the hedonic pathway. The endogenous rewarding effectors enkephalins (Belluzzi and Stein, 1977) (for review, see Koob and Le Moal, 1997) and their physiological peptide antagonist (Faris et al., 1983; Roques and Noble, 1996) cholecystokinin (CCK) that is involved in attention and anxiety (for review, see Daugé and Roques, 1995) may have a role in this defect. However, to our knowledge, the determination of extracellular levels of enkephalins by microdialysis in awake and freely moving rats has not been reported in brain structures involved in opioid dependence after chronic morphine treatments. The levels of these two peptides were therefore measured in control and morphine-treated rats to directly evaluate their possible changes during physical dependence or positive place conditioning (which may reflect the rewarding properties of morphine). This has been performed in this study after implantation of cannulas in brain areas known to be involved in physical dependence [periaqueductal gray matter (PAG)] (Laschka et al., 1976; Maldonado et al., 1992) and positive place conditioning [nucleus accumbens (NAc) and hippocampus] (for review, see Koob and Le Moal, 1997). 


\section{MATERIALS AND METHODS}

Animals. Male Wistar rats (Charles River, Saint-Aubin les Elbeuf, France) weighting 180-200 gm at the time of surgery were used. They were housed in groups of five in a temperature-controlled $\left(22 \pm 1^{\circ} \mathrm{C}\right)$ and humidity-controlled $(50 \pm 5 \%)$ environment and had access to food and water ad libitum. The animals were treated in accordance with the NIH Guidelines for the Care and Use of Laboratory Animals (1985) and in agreement with the local ethical committee.

Chemicals. Morphine $\mathrm{HCl}$ was purchased from Francopia (Route d'Avignon, France), and naloxone $\mathrm{HCl}$ was purchased from Sigma (St. Quentin Fallavier, France). Morphine and naloxone were dissolved in saline $(0.9 \% \mathrm{NaCl})$ and injected intraperitoneally and subcutaneously, respectively, in a final volume of $0.1 \mathrm{ml} / 100$ gm body weight. [ $\left.{ }^{125} \mathrm{I}\right] \mathrm{CCK}_{8}$ was purchased from Amersham Biosciences (Les Ulis, France), and $\left[{ }^{125} \mathrm{I}\right]$ Met-enkephalin was prepared as described previously (Cupo and Jarry, 1985).

Surgery. Rats were anesthetized by an intraperitoneal injection of chloral hydrate $(400 \mathrm{mg} / \mathrm{kg})$, mounted in a stereotaxic apparatus (Unimécanique), and implanted unilaterally with 20 gauge stainless steel cannula guides $(0.6 \mathrm{~mm}$ in external diameter) for microdialysis experiments. Cannulas were positioned $1.5 \mathrm{~mm}$ above the structures. The coordinates, taken from the atlas of Paxinos and Watson (1986), were as follows: (1) $+1.6 \mathrm{~mm}$ anterior to the interaural, $\pm 3.8 \mathrm{~mm}$ lateral to the midline, and $-1.8 \mathrm{~mm}$ under the skull surface for the dorsal subiculum/ CA1 of the hippocampus; (2) $-8.1 \mathrm{~mm}$ anterior from bregma, $\pm 0.5 \mathrm{~mm}$ lateral to the midline, and $-4 \mathrm{~mm}$ under the skull surface for the periaqueductal gray matter; and (3) $+1.2 \mathrm{~mm}$ anterior from bregma, $\pm 0.8 \mathrm{~mm}$ lateral to the midline, and $-6.2 \mathrm{~mm}$ under the skull surface for the NAc. Cannulas were secured to the skull with stainless steel screws and dental cement. Animals were used for experiments after a recovery period of 5-7 d.

Brain dialysis procedure. The dialysis probes, constructed according to the method of Robinson and Whishaw (1988), consisted of a 2.5-mmlong semipermeable polyacrylonitrile AN69 membrane with a molecular size cutoff of 40,000 Da and an external diameter of $0.3 \mathrm{~mm}$, connected to a perfusion system. The probes were inserted in rat brains into chronically implanted cannula guides and positioned to allow permeabilized part of the membrane to cross the structure studied and were maintained in position by a locking screw. Rats were put into individual boxes $(40 \times 40 \times 40 \mathrm{~cm})$ with access to food and water ad libitum $15 \mathrm{hr}$ before the experiments. After this habituation period, the microdialysis probes were connected to a microinjection pump (Precinorm) via a one-channel liquid swivel. The probe was perfused at a flow of $2 \mu \mathrm{l} / \mathrm{min}$ with a dialysis buffer $\left(120 \mathrm{~mm} \mathrm{NaCl}, 5 \mathrm{~mm} \mathrm{KCl}, 1.8 \mathrm{~mm} \mathrm{CaCl}_{2}, 1.2 \mathrm{~mm}\right.$ $\mathrm{MgCl}_{2}, 0.03 \%$ bacitracine, $0.01 \% \mathrm{BSA}$, and $0.2 \mathrm{~mm}$ PBS, $\left.\mathrm{pH} 7.4\right)$. After $2 \mathrm{hr}$ of perfusion, samples were collected every $30 \mathrm{~min}$ in tubes maintained in dry ice. The samples were conserved at $-80^{\circ} \mathrm{C}$ until the quantification of both CCK and Met-enkephalin material by radioimmunoassay (RIA).

Induction of physical dependence and morphine withdrawal. Rats were divided into four groups corresponding to saline, naloxone $(0.5 \mathrm{mg} / \mathrm{kg}$, s.c., twice per day), morphine (doses are indicated below), and morphine plus naloxone $(0.5 \mathrm{mg} / \mathrm{kg}$, s.c., with each dose of morphine). The morphine dose was progressively increased from 7 to $30 \mathrm{mg} / \mathrm{kg}$ (intraperitoneally) over a period of $6 \mathrm{~d}$. The first and second number in parentheses represent the dose of morphine injected, respectively, at 9:00 A.M. and 7:00 P.M., on consecutive days: first day (7 and $10 \mathrm{mg} / \mathrm{kg}$ ), second day ( 15 and $20 \mathrm{mg} / \mathrm{kg}$ ), third day ( 25 and $30 \mathrm{mg} / \mathrm{kg}$ ), fourth and fifth days (30 and $30 \mathrm{mg} / \mathrm{kg}$ ), and sixth day $(30 \mathrm{mg} / \mathrm{kg}$, only at 9:00 A.M.). Rats were connected to dialysis systems after the second injection of morphine on the fifth day and placed in individual boxes. The perfusion with the dialysis buffer started $1 \mathrm{hr}$ after the last injection of morphine (sixth day). After $2 \mathrm{hr}$, the first three samples collected (every $30 \mathrm{~min}$ ) were used to calculate the basal peptide efflux before injection of a single dose of the opioid antagonist naloxone $(1 \mathrm{mg} / \mathrm{kg}$, s.c.) to precipitate the withdrawal syndrome. Then, the samples were collected every 30 min during $90 \mathrm{~min}$. This protocol was used for the four groups of rats.

It was not possible to quantify the behavioral and vegetative signs of withdrawal with rats equipped with the cannulas for microdialysis. Therefore, a control experiment was achieved with rats without brain implantation, chronically treated with morphine as described above to verify the occurrence of physical dependence. On the sixth day, withdrawal was precipitated by a single injection of naloxone hydrochloride (1 $\mathrm{mg} / \mathrm{kg}$, s.c.), and, during a period of $30 \mathrm{~min}$ withdrawal, signs (jumps, wet dog shakes, teeth chattering, ptosis, chewing, and diarrhea) were evaluated as described previously (Maldonado et al., 1992).

Induction of positive place conditioning in the place preference apparatus and measurement of enkephalin and CCK immunoreactivity in microdialyzed brain structures. The conditioning apparatus used in this experiment consisted of a rectangular Plexiglas box divided into two square compartments of the same size $(45 \times 45 \times 30 \mathrm{~cm})$. Two distinctive sensory cues differentiated the compartments: the wall coloring (black or stripes) and the floor texture (grid or smooth). The combination was as follows: black wall-grid floor and striped wall-smooth. The protocol consisted of three phases: (1) habituation (preconditioning) phase (1 d), in which drug naive rats had free access to both compartments of the conditioning apparatus; and (2) conditioning phase (6 d), in which each animal was injected with morphine on alternate days $(5 \mathrm{mg} / \mathrm{kg}$, i.p. $)$ and confined in one compartment (days 1, 3, and 5) for $30 \mathrm{~min}$ or injected with saline and confined in the other compartment (days 2, 4, and 6) for $30 \mathrm{~min}$. One compartment was randomly chosen to be paired to drug administration and the other to vehicle. Control groups were injected with saline every day and placed alternatively in both compartments. At the end of the conditioning phase (on day 7), rats were connected to the microdialysis pumps and placed in individual boxes, as described above in the study of physical dependence. Two hours after the beginning of the perfusion, two samples were collected to determine the basal efflux of neuropeptides. Then animals were transferred in conditioning apparatus (one-half were put in the drug-paired side, and one-half were put in the saline-paired side), and two microdialysis samples were collected. Animals were then replaced in individual boxes, and, $2 \mathrm{hr}$ later, two new samples were collected to determine the basal efflux of the peptides, before introducing the animals in the second compartment of the conditioning apparatus in which two samples were collected (Fig. 1).

In a control experiment, assessment of positive place conditioning was conducted as described previously (Valverde et al., 1996). The protocol consisted in the same three phases described above: (1) preconditioning phase, in which drug naive rats had free access to both compartments of the apparatus, and the time spent in each compartment was recorded; (2) conditioning phase, consisting of 6 consecutive conditioning days ( $3 \mathrm{~d}$ to $5 \mathrm{mg} / \mathrm{kg}$ morphine, i.p., and $3 \mathrm{~d}$ to saline); and (3) testing phase, achieved $24 \mathrm{hr}$ after the last conditioning session and identical to the preconditioning session. The time of occupancy in each compartment was recorded. Results are expressed in scores calculated as the time spent in the drug-associated compartment on the testing day minus the time spent in the drug-associated compartment on the preconditioning day.

Radioimmunoassay of CCK and enkephalin. The quantification of CCK in the dialysates was performed as follows. The C-terminal anti-CCK antibody 8007 (a generous gift from Professor J. Rehfeld, Copenhagen, Denmark) $\left(1: 7.5 \times 10^{-5}\right)$ was incubated at $4^{\circ} \mathrm{C}$ for $4 \mathrm{~d}$ with $\mathrm{CCK}_{8}$ standards or with dialysis samples and $\left[{ }^{125} \mathrm{I}\right] \mathrm{CCK}_{8}$ in the RIA buffer $(20$ $\mathrm{mm}$ barbital buffer, $0.6 \mathrm{~mm}$ thiomersal, and $0.11 \% \mathrm{BSA} \mathrm{v} / \mathrm{v}$; the final $\mathrm{pH}$ was adjusted to 8.4). Bound and free fractions were separated by adsorbing the free $\left[{ }^{125} \mathrm{I}\right] \mathrm{CCK}_{8}$ onto dextran T70 $(4 \mathrm{gm} / \mathrm{l})$ and charcoal $(40 \mathrm{gm} / \mathrm{l})$ in the RIA buffer containing $10 \%$ filtered horse serum. After centrifugation $\left(4000 \mathrm{rpm}, 10 \mathrm{~min}, 4^{\circ} \mathrm{C}\right),\left[{ }^{125} \mathrm{I}\right] \mathrm{CCK}_{8}$ bound to the antibodies was measured in the supernatant by gamma spectrometry using a Wallac counter. Under these conditions, $0.5 \mathrm{pg}$ of CCK can be detected in the dialysates. The percentages of cross- reactivity of CCK antibodies were $50 \%$ for $\mathrm{CCK}_{8} \mathrm{NS}, \mathrm{CCK}_{7} \mathrm{~S}$, and $\mathrm{CCK}_{7} \mathrm{NS}$ and $0.001 \%$ for $\mathrm{CCK}_{5}$ and $\mathrm{CCK}_{4}$. The antiserum used did not bind gastrin peptide (Rehfeld, 1998).

The quantification of enkephalin in the dialysates was performed using the Met-enkephalin antiserum, which has a very low cross-reactivity with Leu-enkephalin $(2 \%)$ and other opioid peptides $(<0.1 \%)$ (Cupo and Jarry, 1985). All of the reagents were diluted in the RIA buffer $(10 \mathrm{~mm}$ disodium phosphate, $150 \mathrm{~mm} \mathrm{NaCl}, 1 \mathrm{gm} / 1 \mathrm{BSA}$, and $0.1 \mathrm{gm} / 1 \mathrm{NaN}_{3}, \mathrm{pH}$ 7.2). Fifty microliters of the antibody dilution (diluted to $1: 75,000$ ), $50 \mu \mathrm{l}$ of the $\left[{ }^{125} \mathrm{I}\right]$ Met-enkephalin $(45000 \mathrm{cpm} / \mathrm{ml}), 60 \mu \mathrm{l}$ of the standard Met-enkephalin, or dialysates were used. After $44 \mathrm{hr}$ of incubation at $4^{\circ} \mathrm{C}$, the assay was stopped by adding $500 \mu \mathrm{l}$ of dextran T70 $(4 \mathrm{gm} / \mathrm{l})$ and charcoal $(40 \mathrm{gm} / \mathrm{l})$ in the RIA buffer containing $10 \%$ filtered horse serum. After centrifugation $\left(4000 \mathrm{rpm}, 10 \mathrm{~min}, 4^{\circ} \mathrm{C}\right),\left[{ }^{125} \mathrm{I}\right] \mathrm{Met}-$ enkephalin bound to the antibodies was measured in the supernatant by gamma spectrometry using a Wallac counter. Under these conditions, 0.1 pg of enkephalin can be detected in the dialysates.

Histological control. Rats were killed with an overdose of chloral hydrate. The brains were removed and frozen in isopentane solution at $-40^{\circ} \mathrm{C}$, and $30 \mu \mathrm{m}$ slices were cut with a microtome. The position of the cannulas or the probes was estimated according to the atlas of Paxinos 


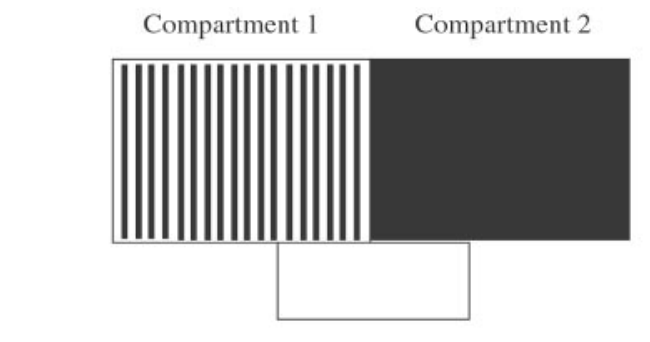

Conditioning phase :

\begin{tabular}{lcc}
\hline & Compartment 1 & Compartment 2 \\
\hline Group 1 (6 rats) & Saline (day 1,3,5) & Saline (day 2,4,6) \\
Group 2 (6 rats) & Saline (day 2,4,6) & Saline (day 1,3,5) \\
Group 3 (6 rats) & Morphine (day 1,3,5) & Saline (day 2,4,6) \\
Group 4 (6 rats) & Saline (day 2,4,6) & Morphine (day 1,3,5) \\
\hline
\end{tabular}
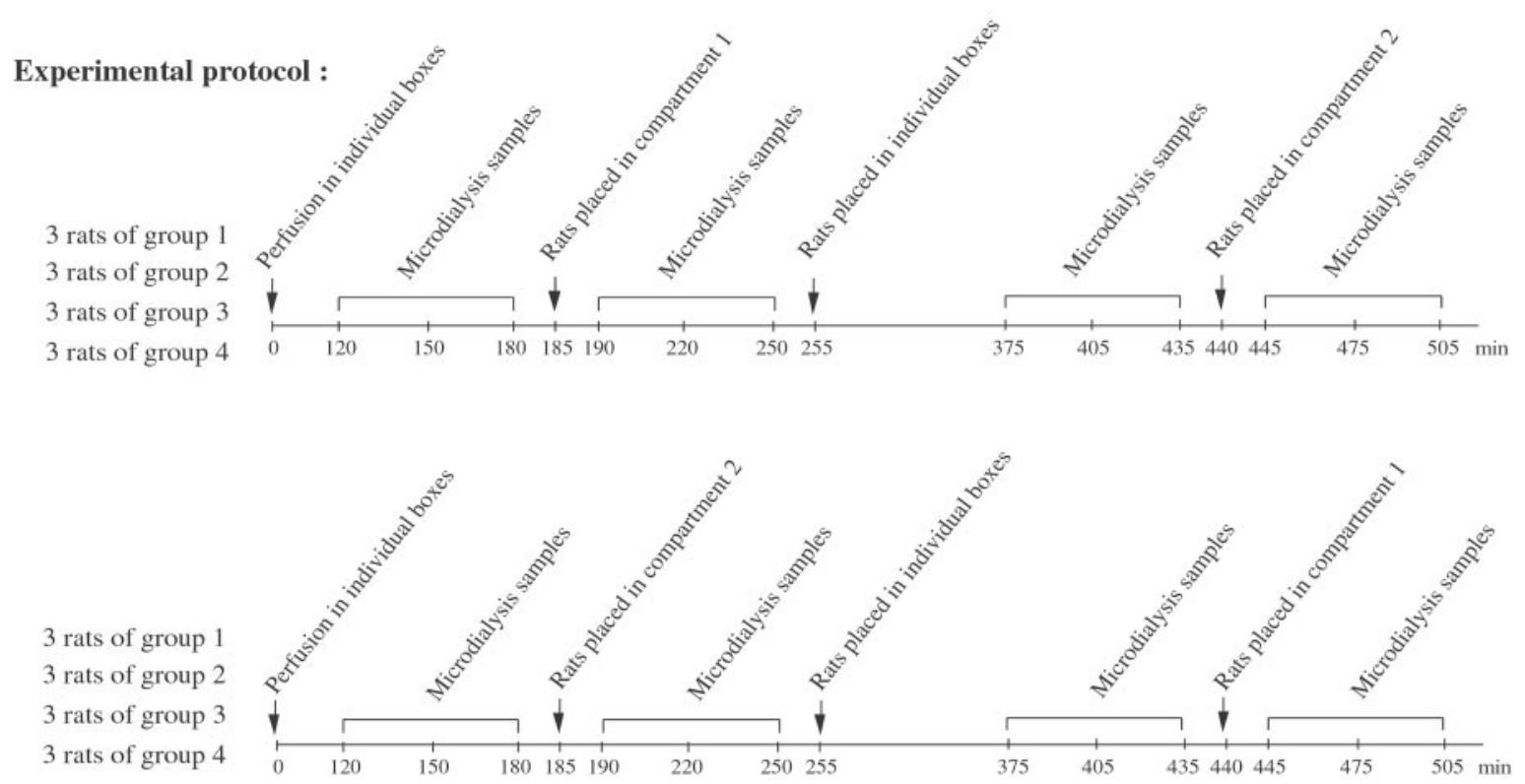

Figure 1. Summary of the experimental protocols used in the conditioning phase and the microdialysis experiments to determine the extracellular levels of Met-enkephalin and CCK immunoreactivity.

and Watson (1986). Only the data from rats having probes that traversed $70 \%$ of the investigated structures were retained for calculations (data not shown).

Statistical analysis. Data were analyzed by one-way ANOVA, followed by a Newman-Keuls test

\section{RESULTS}

\section{Levels of enkephalin in the PAG of rats after induction of physical dependence and morphine withdrawal}

The mean of the basal extracellular levels of enkephalin in the PAG of control rats chronically treated with saline measured for $180 \mathrm{~min}$ was found to be $0.59 \pm 0.02 \mathrm{pg} / \mathrm{sample}(n=6)$. There was no significant change in the extracellular levels of this neuropeptide according to the time, and a single injection of naloxone at $t=90$ min did not modify the enkephalin levels (Fig. 2). The same results were obtained with rats chronically treated with naloxone alone.

In contrast, the extracellular levels of enkephalin were significantly increased in rats chronically treated for $5 \mathrm{~d}$ with morphine compared with control rats, with a mean of $2.16 \pm 0.24 \mathrm{pg} /$ sample, before injection of naloxone. This large increase in enkephalin levels was totally blocked when the animals were chronically cotreated with the opioid antagonist naloxone (Fig. 2). The increase observed may not be attributable to an acute effect of morphine, because the first samples were collected $3 \mathrm{hr}$ after the last injection of morphine, and it was reported in the literature that the alkaloid increased extracellular opioid peptide levels over a $2 \mathrm{hr}$ period, peaking $1 \mathrm{hr}$ after injection (Olive et al., 1995).

Morphine withdrawal was precipitated by injection of the opi- oid antagonist naloxone $(1 \mathrm{mg} / \mathrm{kg}$, s.c. $)$ at $t=90 \mathrm{~min}$. Classical behavioral manifestations of the withdrawal were observed as expected in the group of rats chronically treated by morphine alone. Nevertheless, the behavioral signs of physical dependence could not be quantified, because the microdialysis system did not afford an easy measurement of this syndrome (jumps, wet-dog shakes, paw tremor, ... ). However, in a parallel experiment achieved strictly in the same experimental conditions, except that the rats were not equipped with perfusion material, we verified the naloxone-induced signs of physical dependence. Thus, naloxone administration precipitated the standard behavioral signs of withdrawal (increase in jumps, wet dog shakes, teeth chattering, ptosis, chewing, and diarrhea) in morphine-treated animals but not in saline-injected control groups (Fig. 3).

Radioimmunoassay of the dialysis samples after injection of naloxone showed that precipitation of the withdrawal syndrome did not modify the extracellular levels of enkephalin in the PAG of morphine-dependent rats. Thus, the mean of the extracellular level of this neuropeptide was $\sim 2.01 \pm 0.17 \mathrm{pg} / \mathrm{sample}$ after injection of the opioid antagonist, which was not statistically different from the level determined before naloxone administration $(2.16 \pm 0.24 \mathrm{pg} / \mathrm{sample})$.

\section{Extracellular levels of CCK in the PAG of rats after induction of physical dependence and morphine withdrawal}

The results reported in Figure 4 show that no difference was observed in the extracellular levels of CCK in the PAG of rats 


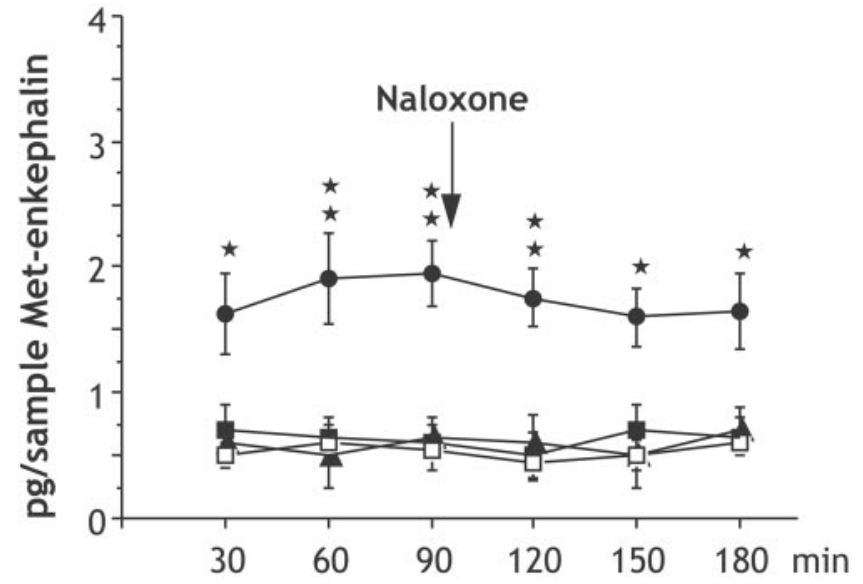

Figure 2. Increase in extracellular levels of enkephalin produced by chronic morphine treatment in the PAG of rats. Animals were chronically treated with saline $(\square)$, naloxone $(0.5 \mathrm{mg} / \mathrm{kg}$, s.c.; $\mathbf{\Delta})$, morphine $(\bullet)$, or

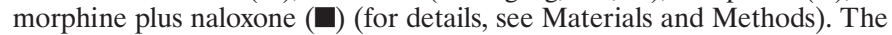
dialysis samples were collected every $30 \mathrm{~min}$. After $90 \mathrm{~min}$, a single dose of naloxone $(1 \mathrm{mg} / \mathrm{kg}$, s.c.) was injected in each groups of rats. Results are expressed as mean \pm SEM of enkephalin in picograms per sample $(n=$

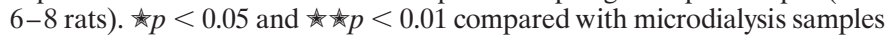
collected from control rats at the same time (Newman-Keuls test).

chronically treated with morphine compared with control rats. Moreover, no significant change in the levels of this neuropeptide was observed according to the time, and, after precipitation of the morphine withdrawal after acute injection of the opioid antagonist naloxone (1 $\mathrm{mg} / \mathrm{kg}$, s.c.), a slight, although nonsignificant, enhancement of CCK outflow was observed in morphinedependent rats compared with control animals.

\section{Extracellular levels of enkephalin in the NAc of rats after induction of a positive place conditioning}

As shown in Figure $5 A$, the mean of the basal extracellular levels of enkephalin in control rats was $\sim 2.36 \pm 0.27 \mathrm{pg} / \mathrm{sample}(n=8)$. There was no significant change in the levels of this neuropeptide according to the time and the compartment in which the animals were placed in the conditioning apparatus.

The basal efflux of enkephalin in the NAc of rats conditioned with morphine was not significantly different from that of control rats. When the animals were placed in the morphine-paired compartment, the analysis of the microdialysis samples showed a large increase $(160 \%)$ in the extracellular levels of enkephalin. This maximum increase occurred 30 min after introduction of the animals in the rewarding side. In contrast, when the animals were placed in the saline-paired compartment, a significant decrease of the extracellular level of enkephalin was observed compared with basal level, with a time effect similar to that found in the morphine-paired compartment.

As for the morphine-induced physical dependence, we determined in a preliminary experiment that the experimental conditions used induced a positive place conditioning. One-way ANOVA revealed a conditioned place preference in rats treated with morphine $(5 \mathrm{mg} / \mathrm{kg})$ administered intraperitoneally $\left(F_{(1,18)}=\right.$ 27.506; $p<0.001$ ) (Fig. 5B).

\section{Extracellular levels of CCK in the NAc of rats after induction of a positive place conditioning}

As shown in Figure $6 A$, the extracellular levels of CCK in the NAc of rats conditioned with morphine was not different from
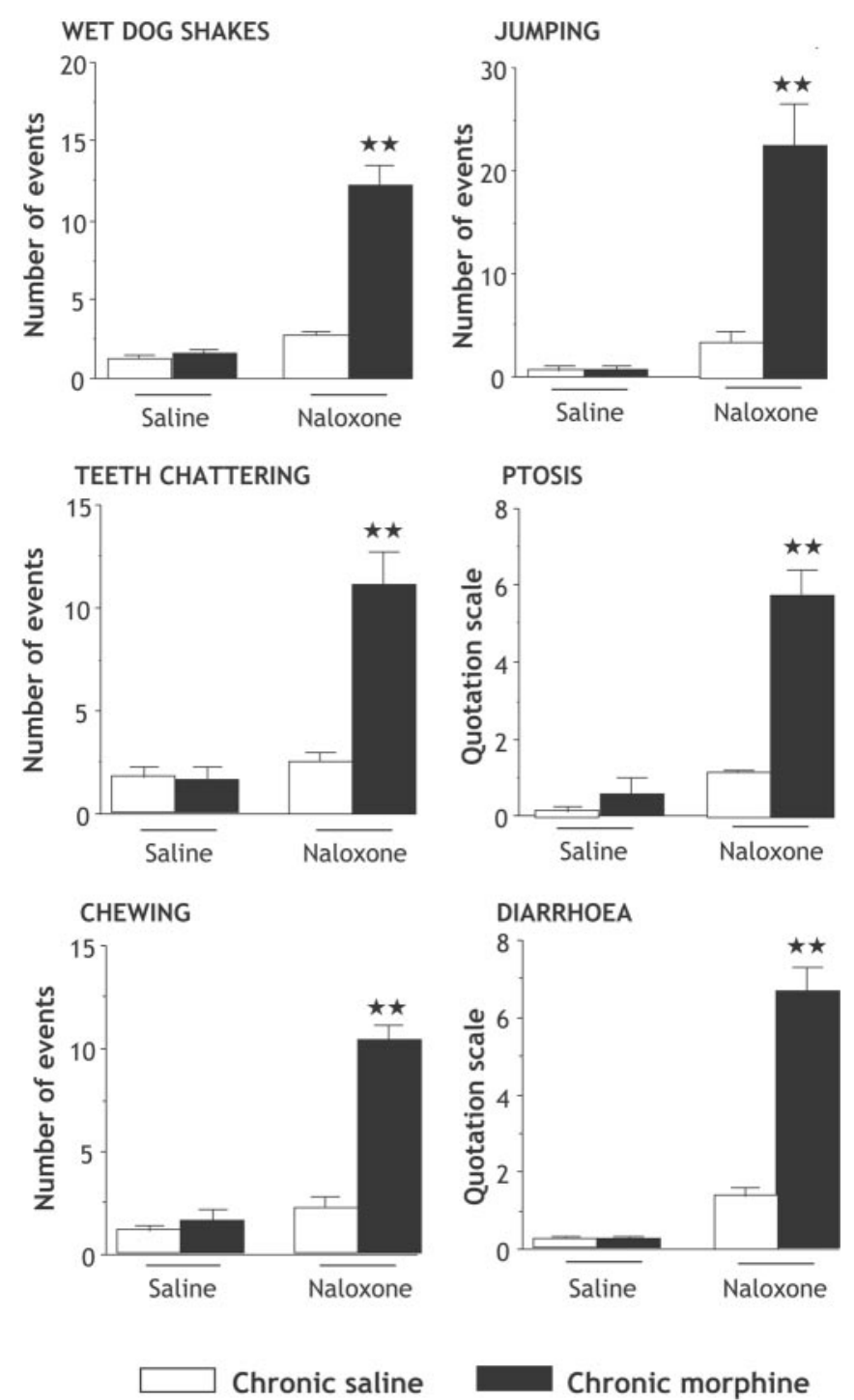

Figure 3. Effects of saline or naloxone administration $(1 \mathrm{mg} / \mathrm{kg}$, s.c.) on behavior in rats chronically treated with saline $(\square)$ or morphine (ם) for $6 \mathrm{~d}$ (for details, see Materials and Methods). The results are expressed as mean \pm SEM of the number of events counted (wet dog shakes, jumps, teeth chattering, and chewing) or according to the quotation scale established: one point was given for the presence of each sign over $5 \mathrm{~min}$ periods (ptosis and diarrhea) during the $40 \mathrm{~min}$ period of observation immediately after naloxone injection. $n=8-10$ animals per group. 触 $p<0.01$ compared with rats chronically treated with saline, receiving an acute injection of naloxone (Newman-Keuls test).

that of control rats, even when the animals were placed in the morphine- or saline-paired compartment.

\section{Extracellular levels of CCK in the dorsal subiculum/ CA1 of the hippocampus of rats after morphine- induced positive place conditioning}

No difference was observed in the extracellular levels of CCK in the dorsal subiculum/CA1 of the hippocampus in control and morphine-treated rats. Moreover, there was no significant effect on the extracellular levels of CCK in this brain area (Fig. 6B) when the morphine-treated rats were placed in the drug-paired side or saline-paired side. 


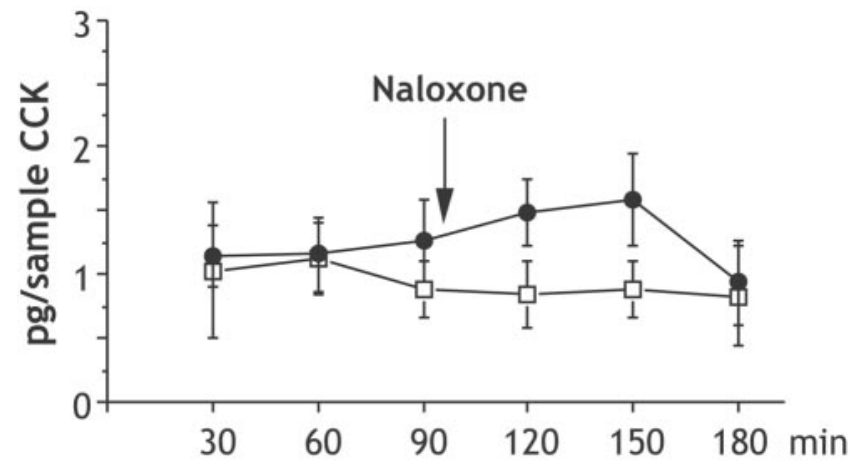

Figure 4. Determination of the extracellular levels of CCK in the PAG of rats chronically treated with saline $(\square)$ or morphine $(\bullet)$ as described in Materials and Methods, before and after administration of naloxone (1 $\mathrm{mg} / \mathrm{kg}$, s.c.). The dialysis samples were collected every $30 \mathrm{~min}$. Results are expressed as mean \pm SEM of CCK in picograms per sample $(n=6-8$ rats).

\section{DISCUSSION}

This study provides evidence for the first time that chronic morphine treatment may directly modulate the extracellular levels of enkephalin in brain areas involved in physical dependence and positive place conditioning. Thus, an important increase of opioid peptides concentration has been measured in the PAG after chronic morphine treatment, and, using the place preference paradigm, opposite changes of enkephalin outflow in the NAc was observed, with an increase in the morphine-paired side that could reflect an anticipation of reward and a decrease in saline-paired side that may be related to an anhedonic state.

\section{Chronic morphine treatment enhances enkephalin, but} not CCK, outflow in the PAG

An important increase (340\%), not significantly modified during the naloxone-precipitated withdrawal syndrome, of enkephalin outflow was observed in morphine-dependent rats compared with control animals in the PAG, a structure that plays a major role in the withdrawal syndrome (Laschka et al., 1976; Maldonado et al., 1992). This enhanced opioid peptide release involves very likely opioid receptor overstimulation because it was prevented by cotreatment with naloxone. It reflects probably an enhanced expression of preproenkephalin gene in morphine-dependent rats, consistent with the reported enhancement of preproenkephalin mRNA in PAG during opioid withdrawal (Fukunaga et al., 1996, 1998). This is also supported by the reported increase of enkephalin into cat brain chronically treated with morphine using the technique of perfusion (Jhamandas et al., 1984).

Several mechanisms could be proposed to explain these results. The increase of enkephalin measured in the PAG observed here and the reported increase in preproenkephalin gene expression are consistent with the well established increase in adenylyl cyclase activity after chronic opioid treatment (for review, see Cox, 1993; Matsuoka et al., 1994; Nestler and Aghajanian, 1997), resulting in an upregulation of the cAMP pathway. This leads to increased levels of cAMP response element-binding activity, which in turn should increase expression of the proenkephalin gene and extracellular enkephalin levels (Comb et al., 1986; Van Nguyen et al., 1990; Simpson and McGinty, 1995). Another explanation could be related to the observed greater inhibition of GABAergic synaptic transmission in slices from morphinedependent rats than from control animals (Ingram et al., 1998), resulting in inhibition of the negative feedback onto enkephalin-
A

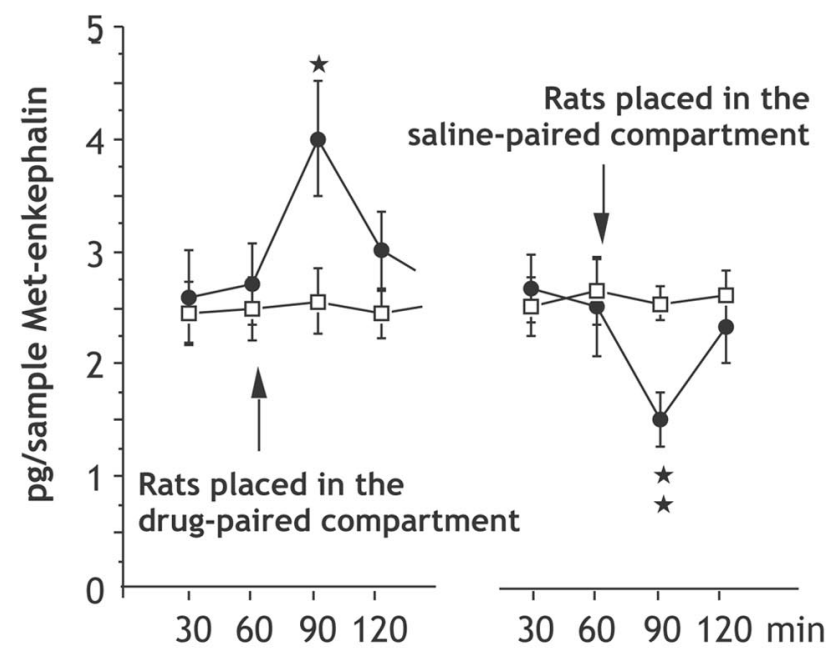

B

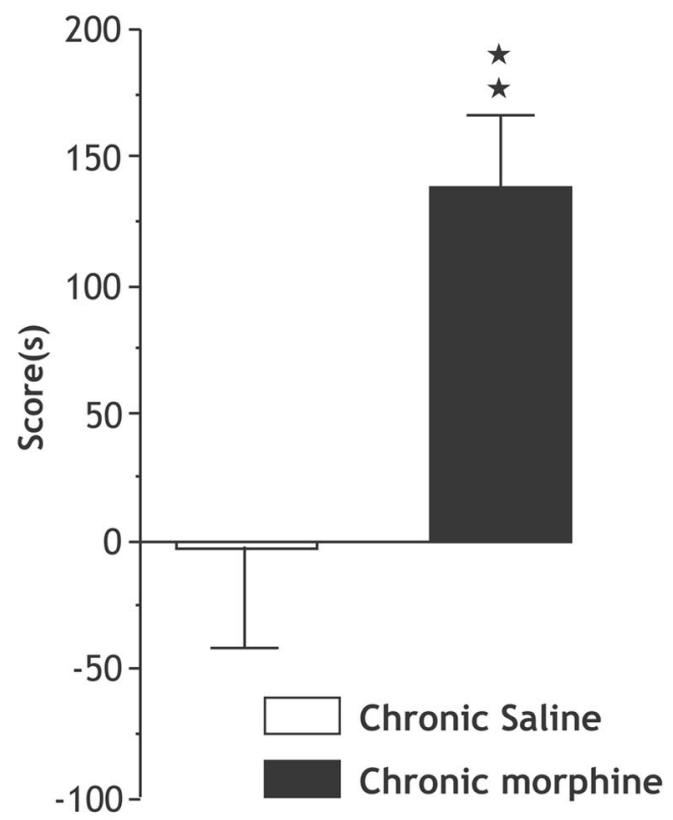

Figure 5. A, Determination of the extracellular levels of enkephalin in the nucleus accumbens of rats chronically treated with saline $(\square)$ or morphine (O) to induce a positive place conditioning as described in Materials and Methods. The dialysis samples were collected every $30 \mathrm{~min}$. Results are expressed as mean \pm SEM of enkephalin in picograms per sample $(n=6-8$ rats). $n p<0.05$ and $p<p<0.01$ compared with microdialysis samples collected from control rats placed in the same conditions (Newman-Keuls test). $B$, Conditioned place preference induced by morphine $(5 \mathrm{mg} / \mathrm{kg}$, i.p.). Data are expressed as scores (mean \pm SEM) calculated as the difference between postconditioning and preconditioning time spent in the compartment associated with the drug. $n=8$ rats per group.

ergic neurons or terminals and thus increasing the release of enkephalin (Williams et al., 1995).

The large increase in synaptic levels of enkephalin tone in the PAG in opioid-dependent rats leads to a new state of the enkephalinergic neural circuitry that is not modified after naloxone administration. This lack of compensatory increase in extracellular amounts of endogenous enkephalins could participate to the 
A

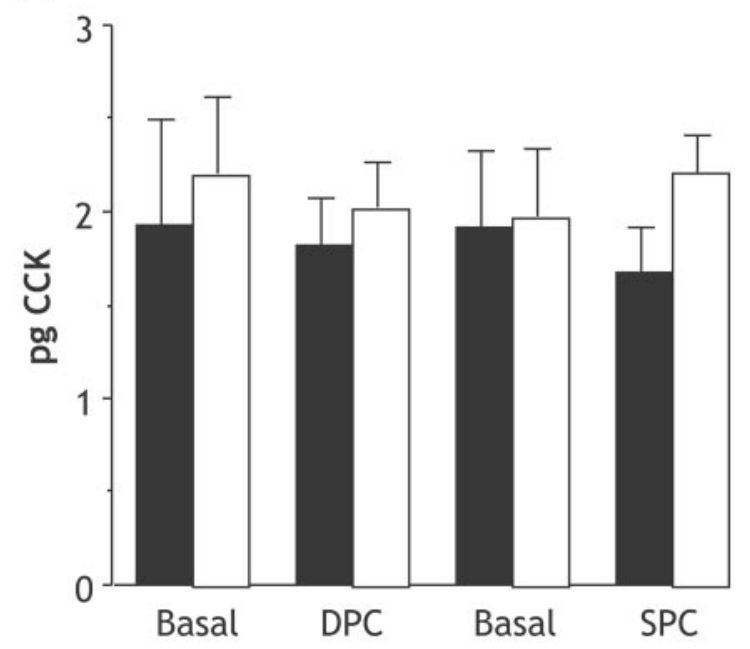

B

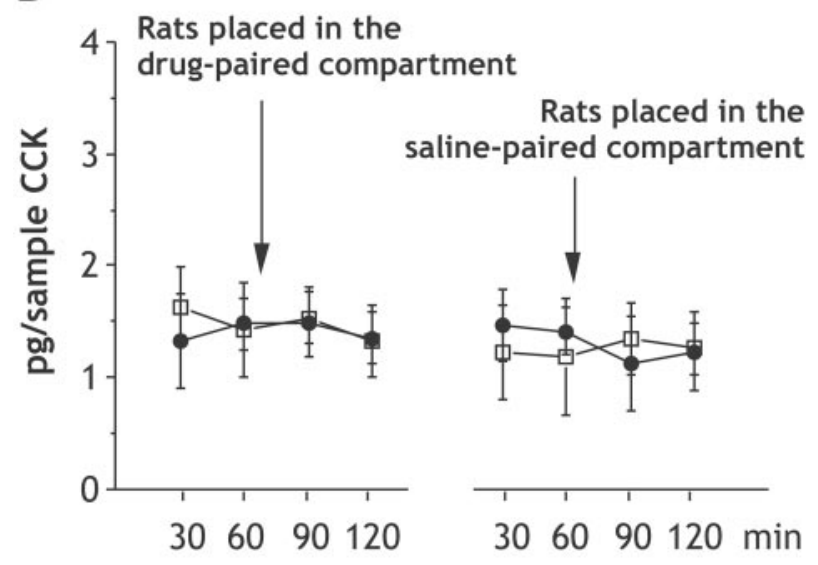

Figure 6. Determination of the extracellular levels of CCK in the nucleus accumbens $(A)$ and the dorsal subiculum/CA1 of the hippocampus $(B)$ of rats chronically treated with saline $(\square)$ or morphine $(\bullet)$ to induce a positive place conditioning as described in Materials and Methods. The dialysis samples were collected every $30 \mathrm{~min}$, and two samples were pooled to facilitate the radioimmunologic determination of CCK. DPC, Drug-paired compartment; $S P C$, saline-paired compartment. Results are expressed as mean \pm SEM of CCK in picograms $(n=6-8$ rats $)$.

withdrawal syndrome. Consistent with this hypothesis, an increase in endogenous enkephalins induced by peptidase inhibitors microinjected into the PAG inhibit naloxone-precipitated withdrawal in morphine-dependent rats (Haffmans and Dzoljic, 1987; Maldonado et al., 1992), and direct injection of enkephalins in rodent brain reduced morphine withdrawal (Bhargava, 1977).

The lack of modification in the CCK outflow in morphinedependent rats compared with controls is consistent with the observation that the CCKergic system is not involved in morphine dependence, an hypothesis suggested previously by behavioral experiments showing that chronic CCK receptor blockade was unable to prevent morphine dependence (Panerai et al., 1987; Dourish et al., 1990; Xu et al., 1992). However, when CCK immunoreactivity was measured in the cisternal CSF of rats that had received a chronic morphine treatment, a $70 \%$ increase on the first day, a $39 \%$ increase on the third day, and a return to the control level on the sixth day were observed (Zhou et al., 1993), indicating that the time between the beginning of chronic mor- phine treatment and the determination of brain CCK is crucial. This observation may explain the discrepancy between the lack of change in the CCK outflow observed in the present study and the significant increase reported by Becker et al. (2000) after only $3 \mathrm{~d}$ of chronic morphine treatment. Nevertheless, it cannot also be excluded that the difference between both studies is only attributable to distinct regulation of CCK systems by morphine in the PAG (present study) and in the frontal cortex (Becker et al., 2000).

\section{Enkephalin outflow in the NAc is modified by the induction of positive place conditioning}

All of the drugs of abuse were shown to increase extracellular dopamine levels in the shell part of the NAc (Di Chiara and Imperato, 1988) (for review, see Spanagel and Weiss, 1999). This rewarding process is thought to induce an addictive state after repetitive drug consumption. This can be measured using the conditioned place preference paradigm, considered closer to addictive situations in humans than the self-administration procedure (Van Ree et al., 1999). In this test, animals were confined alternatively in distinct compartments under reinforced (morphine injection) or nonreinforced (saline injection) conditions. In this model, opposite changes in the enkephalin outflow in the NAc were observed (Fig. 5). Thus, enkephalin was found enhanced in the drug-paired compartment and reduced in the saline-paired one. On the other hand, no modification in the extracellular levels of CCK was observed. The neurons of NAc receive an intense dopaminergic innervation from the ventral tegmental area, critically involved in reward and drug dependence (for review, see Koob and Le Moal, 1997; Maldonado et al., 1997; Di Chiara, 1999), and glutamatergic projections from the hippocampus, the prefrontal cortex, and the amygdala (Groenewegen et al., 1991). Interestingly, anatomical data showed that CCKergic terminals establish direct synaptic contact with glutamatergic neurons of the hippocampus that project to the NAc (Totterdell and Smith, 1986). Thus, putative changes in the CCK outflow in the dorsal subiculum/CA1 of the hippocampus were also investigated during the expression of morphine-induced positive place conditioning. However, no change in the extracellular levels of CCK were observed when the animals were placed in drug- or saline-paired compartments, suggesting that modifications of the CCK outflow is not essential, at least in the expression of a morphine-conditioned place preference.

The transient increase in enkephalin efflux observed in the NAc when the animals were placed in the drug-paired compartment during the microdialysis experiment may reflect an anticipation of the rewarding effect, associated with the memory of the reinforcing effects obtained with morphine in this compartment during the conditioning phase. It is interesting to note that this increase also occurs in response to the drug itself, because it has been shown that systemic acute morphine administration may induce an increase in enkephalin release in the pallidum, which receives dense enkephalinergic innervation from the NAc (Olive et al., 1995; Olive and Maidment, 1998). In contrast, when the rats were placed in the saline-paired compartment, a decrease in the extracellular level of enkephalin was observed that may be related to an aversive effect. In this line, several studies have clearly demonstrated a role for endogenous opioid peptides in the perception of reward and in the mediation of behavioral reinforcement. Thus, it has been shown that water deprivation induced a reduction in opioid release and that this effect was reversed in animals receiving water (Blake et al., 1987). The increase of opioids 
observed may contribute to the perception of reward. Thus, injection of enkephalin in the NAc may serve as reinforcement for self-administration behavior (Stein and Belluzzi, 1979; Goeders et al., 1984), and an increased level of endogenous opioid peptides was observed when the compulsive drug seeking for drugs of abuse is high in the self-administration procedure (Cappendijk et al., 1999; Gerrits et al., 1999).

The results suggest that enkephalins may be a neural substrate for reward expectation, as previously suggested for dopamine (Schultz et al., 1997; Garris et al., 1999). A signal may be delivered when the animal is placed in the drug-paired compartment, increasing the release of enkephalins, which may influence the processing of predictions and the choice of reward-maximizing action. This process may be either of the following: (1) dopamine independent, only involving opioid receptors localized postsynaptically in the NAc, as demonstrated previously in the maintenance of heroin self-administration (for review, see Koob, 1992); or (2) dopamine dependent, consistent with the demonstration that activation of $\mu$ or $\delta$ opioid receptors in the NAc increased dopamine release (Spanagel et al., 1990; Yokoo et al., 1994). Thus, activation of $\mu$ and/or $\delta$ opioid receptors by a high level of enkephalins may lead to an increased release of dopamine, whereas reduction of their stimulation by a low level of endogenous opioid peptides may reduce the dopamine tone, resulting in a subsequent decrease in the activity of $D_{1}$ receptors present in the NAc. This regulation of extracellular dopamine efflux may be important in the expression of morphine-induced positive place conditioning, because opioid reward measured by the conditioned place preference paradigm depends on midbrain dopaminerelated mechanisms (Bozarth, 1987; Bals-Kubik et al., 1993).

In conclusion, these data show that enkephalin outflow is regulated after chronic morphine treatment inducing physical dependence and positive place conditioning in brain structures known to play a major role in the development-expression of these effects. In contrast, no regulation of CCK release was observed, suggesting that the modulatory interactions between CCK and opioid, primarily studied through behavioral experiments, may involve post-receptor events without necessarily inducing changes in peptide release. The signal transduction induced by activation of the CCK receptors may cross talk with intracellular mechanisms occurring after stimulation of opioid receptors.

\section{REFERENCES}

Bals-Kubik R, Ableitner A, Herz A, Shippenberg TS (1993) Neuroanatomical sites mediating the motivational effects of opioids as mapped by the conditioned place preference paradigm in rats. J Pharmacol Exp Ther 264:489-495.

Becker C, Pohl M, Thiébot MH, Collin E, Hamon M, Cesselin F, Benoliel JJ (2000) Delta-opioid receptor-mediated increase in cortical extracellular levels of cholecystokinin-like material by subchronic morphine in rats. Neuropharmacology 39:161-171.

Belluzzi JD, Stein L (1977) Enkephalin may mediate euphoria and drive-reduction reward. Nature 266:556-558.

Bhargava HN (1977) Opiate-like action of methionine-enkephalin in inhibiting morphine abstinence syndrome. Eur J Pharmacol 41:81-84.

Blake MJ, Stein EA, Czech DA (1987) Drinking-induced alterations in reward pathways: an in vivo autoradiographic analysis. Brain Res 413:111-119.

Bozarth MA (1987) neuroanatomical boundaries of the reward-relevant opiate-receptor field in the ventral tegmental area as mapped by the conditioned place preference method in rats. Brain Res 414:77-84.

Cappendijk SLT, Hurd YL, Nylander I, Van Ree JM, Terenius L (1999) A heroin-, but not cocaine-expecting, self-administration state preferentially alters endogenous brain peptides. Eur J Pharmacol 365:175-182.

Comb M, Birnberg NC, Seasholtz A, Herbert E, Goodman HM (1986) A cyclic AMP- and phorbol ester-inducible DNA element. Nature 353-356.

Cox BM (1993) Opioid receptor-G protein interactions: acute and chronic effects of opioids. In: Handbook of experimental pharmacology, Opioids I (Herz A, ed), pp 145-188. Berlin: Springer.

Cupo A, Jarry T (1985) Detection of methionine-enkephalin at the 10 (-16) mole level. J Neuroimmunol 8:57-67.

Daugé V, Roques BP (1995) Opioid and CCK systems in anxiety and reward. In: Cholecystokinin and anxiety: from neuron to behavior (Bradwejn J, Vasar E, eds), pp 151-171. Berlin: Springer.

Di Chiara G (1999) Drug addiction as dopamine-dependent associative learning disorder. Eur J Pharmacol 375:13-30.

Di Chiara G, Imperato A (1988) Drugs abused by humans preferentially increase synaptic dopamine concentrations in the mesolimbic system of freely moving rats. Proc Natl Acad Sci USA 85:5274-5278.

Dourish CT, O'Neill MF, Couglan J, Kitchener SJ, Hawley D, Iversen SD (1990) The selective CCK-B antagonist L-365,260 enhances morphine analgesia and prevents morphine tolerance in rat. Eur J Pharmacol 175:35-44.

Ettenberg A, Petit HO, Bloom FE, Koob GF (1982) Heroin and cocaine intravenous self-administration in rats. Mediation by separate neural systems. Psychopharmacologia 78:204-209.

Faris PL, Komisaruk BR, Watkins LR, Mayer DJ (1983) Evidence for the neuropeptide cholecystokinin as an antagonist of opiate analgesia. Science 219:310-312.

Fukunaga Y, Nishida S, Inoue N, Kishioka S, Yamamoto H (1996) Increase of preproenkephalin mRNA in the caudal part of periaqueductal gray by morphine withdrawal in rats: a quantitative in situ hybridization study. Mol Brain Res 42:128-130.

Fukunaga Y, Nishida S, Inoue N, Miyamoto M, Kishioka S, Yamamoto H (1998) Time course of morphine withdrawal and preproenkephalin gene expression in the periaqueductal gray of rats. Mol Brain Res 55:221-231.

Garris PA, Kilpatrick M, Bunin MA, Michael D, Walker QD, Wightman RM (1999) Dissociation of dopamine release in the nucleus accumbens from intracranial self-stimulation. Nature 398:67-69.

Gerrits M, Wiegant VM, Van Ree JM (1999) Endogenous opioids implicated in the dynamics of experimental drug addictions: an in vivo autoradiographic analysis. Neuroscience 89:1219-1227.

Goeders NE, Lane JD, Smith JE (1984) Self-administration of methionine enkephalin into the nucleus accumbens. Pharmacol Biochem Behav 20:451-455.

Groenewegen HJ, Berendse HW, Meredith GE, Haber SN, Voorn P, Wolters JG, Lohman AHM (1991) Functional anatomy of the ventral limbic system-innervated striatum. In: The mesolimbic dopamine system: from motivation to action (Willner P, Scheel-Krüger J, eds), pp 19-59. New York: Wiley.

Haffmans J, Dzoljic MR (1987) Inhibition of enkephalinase activity attenuates naloxone-precipitated withdrawal symptoms. Gen Pharmacol 18:103-105.

Herz A (1997) Endogenous opioid systems and alcohol addiction. Psychopharmacology 129:99-111.

Ingram SL, Vaughan CW, Bagley EE, Connor M, Christie MJ (1998) Enhanced opioid efficacy in opioid dependence is caused by an altered signal transduction pathway. J Neurosci 18:10269-10276.

Jhamandas K, Yaksh TL, Go VLM (1984) Acute and chronic morphine modifies the in vivo release of methionine enkephalin-like immunoreactivity from the cat spinal cord and brain. Brain Res 297:91-103.

Koob GF (1992) Drugs of abuse: anatomy, pharmacology and function of reward pathways. Trends Pharmacol Sci 13:177-184.

Koob GF, Le Moal M (1997) Drug abuse: hedonic homeostatic dysregulation. Science 278:52-58.

Kornet M, Goosen G, Van Ree JM (1991) Effect of naltrexone on alcohol consumption during chronic alcohol drinking and after a period of imposed abstinence in free-choice drinking rhesus monkeys. Psychopharmacology 104:367-376.

Kornetsky C, Bain G (1982) Biobehavioral bases of the reinforcing properties of opiate drugs. Ann NY Acad Sci 398:241-259.

Laschka E, Teschemacher H, Mehraein P, Herz A (1976) Sites of action of morphine involved in the development of physical dependence in rats. II. Morphine withdrawal precipitated by application of morphine antagonists into restricted parts of the ventricular system and by microinjection into various brain areas. Psychopharmacologia 46:141-147.

Lightman SL, Young WS (1987) Changes in hypothalamic preproenkephalin A mRNA following stress and opiate withdrawal. Nature 328:643-645.

Maldonado R, Stinus L, Gold L, Koob GF (1992) Role of different brain structures in the expression of the physical morphine withdrawal syndrome. J Pharmacol Exp Ther 261:669-677.

Maldonado R, Saiardi A, Valverde O, Samad TA, Roques BP, Borrelli E (1997) Absence of opiate rewarding effects in mice lacking dopamine D2 receptors. Nature 388:586-589.

Matsuoka I, Maldonado R, Defer N, Noël F, Hanoune J, Roques BP (1994) Chronic morphine administration causes region-specific increase of brain type VIII adenylyl cyclase mRNA. Eur J Pharmacol 268:215-221.

Negus SS, Henriksen SJ, Mattox A, Pasternak GW, Takemori AE, Weinger MB, Koob GF (1993) Effect of antagonists selective for mu, 
delta and kappa opioid receptors on the reinforcing effects of heroin in rats. J Pharmacol Exp Ther 265:1245-1252.

Nestler EJ, Aghajanian GK (1997) Molecular and cellular basis of addiction. Science 278:58-63.

O'Brien CP, Volpicelli LA, Volpicelli JR (1996) Naltrexone in the treatment of alcoholism: a clinical review. Alcohol 13:35-39.

Olive MF, Maidment NT (1998) Repeated heroin administration increases extracellular opioid peptide-like immunoreactivity in the globus pallidus/ventral pallidum of freely moving rats. Psychopharmacology 139:251-254.

Olive MF, Bertolucci M, Evans CJ, Maidment NT (1995) Microdialysis reveals a morphine-induced increase in pallidal opioid peptide release. NeuroReport 6:1093-1096.

O'Malley SS (1996) Opioid antagonists in the treatment of alcohol dependence: clinical efficacy and prevention of relapse. Alcohol 1:77-81.

Oslin DW, Pettinati HM, Volpicelli JR, Wolf AL, Kampman KM, O'Brien CP (1999) The effects of naltrexone on alcohol and cocaine use in dually addicted patients. J Subst Abuse Treat 16:163-167.

Panerai AE, Rovati LC, Cocco E, Sacerdote P, Mantegazza P (1987) Dissociation of tolerance and dependence to morphine: a possible role for cholecystokinin. Brain Res 410:52-60.

Paxinos G, Watson C (1986) The rat brain in stereotaxic coordinates. New York: Academic.

Rehfeld JF (1998) Accurate measurement of cholecystokinin in plasma. Clin Chem 44:991-1001.

Robinson TE, Whishaw IQ (1988) Normalization of extracellular dopamine in striatum following recovery from a partial unilateral 6-OHDA lesion of the substantia nigra: a microdialysis study in freely moving rats. Brain Res 450:209-224.

Roques BP, Noble F (1996) Association of enkephalin catabolism inhibitors and CCK-B antagonists: a potential use in the management of pain and opioid addiction. Neurochem Res 21:1395-1409.

Samson HH, Doyle TF (1985) Oral ethanol self-administration in the rat: effect of naloxone. Pharmacol Biochem Behav 22:91-99.

Schmitz JM, Stotts AL, Rhoades HM, Grabowski J (2001) Naltrexone and relapse prevention treatment for cocaine-dependent patients. Addict Behav 26:167-180.

Schultz W, Dayan P, Montague PR (1997) A neural substrate of prediction reward. Science 275:1593-1599.

Simpson JN, McGinty JF (1995) Forskolin induces preproenkephalin and preprodynorphin mRNA in rat striatum as demonstrated by in situ hybridization histochemistry. Synapse 19:151-159.

Spanagel R, Weiss F (1999) The dopamine hypothesis of reward: past and current status. Trends Neurosci 22:521-527.

Spanagel R, Herz A, Shippenberg TS (1990) The effects of opioid pep- tides on dopamine release in the nucleus accumbens: an in vivo microdialysis study. J Neurochem 55:1734-1740.

Stein L, Belluzzi JD (1979) Brain endorphins: possible role in reward and memory formation. Fed Proc 38:2468-2472.

Tejwani GA, Rattan AK (1997) Met-enkephalin alteration in the rat during chronic injection of morphine and/or midazolam. Brain Res 775:119-126.

Tjon GH, Voorn P, Vanderschuren LJ, de Vries TJ, Michiels NH, Jonker AJ, Klop H, Nestby P, Mulder AH, Schoffelmeer AN (1997) Delayed occurrence of enhanced striatal preprodynorphin gene expression in behaviorally sensitized rats: differential long-term effects of intermittent and chronic morphine administration. Neuroscience 76:167-176.

Totterdell S, Smith AD (1986) Cholecystokinin-immunoreactive boutons in synaptic contact with hippocampal pyramidal neurons that project to the nucleus accumbens. Neuroscience 19:181-192.

Valverde O, Fournié-Zaluski MC, Roques BP, Maldonado R (1996) The CCK-B antagonist PD-134,308 facilitates rewarding effects of endogenous enkephalins but does not induce place preference in rats. Psychopharmacology 123:119-126.

Van Bockstaele EJ, Peoples J, Menko AS, McHugh K, Drolet G (2000) Decreases in endogenous opioid peptides in the rat medullo-coerulear pathway after chronic morphine treatment. J Neurosci 20:8659-8666.

Van Nguyen T, Kobierski L, Comb M, Hyman SE (1990) The effect of depolarization on expression of the human proenkephalin gene is synergistic with cAMP and dependent upon a cAMP-inducible enhancer. J Neurosci 10:2825-2833.

Van Ree JM, Gerrits MA, Vanderschuren LJ (1999) Opioids, reward and addiction: an encounter of biology, psychology, and medicine. Pharmacol Rev 51:341-396.

Williams FG, Mullet MA, Beitz AJ (1995) basal release of Metenkephalin and neurotensin in the ventrolateral periaqueductal gray matter of the rat: a microdialysis study of antinociceptive circuits. Brain Res 690:207-216.

Xu XJ, Wiesenfeld-Hallin Z, Hughes J, Horwell DC, Hökfelt T (1992) CI 988, a selective antagonist of cholecystokinin-B receptors, prevents morphine tolerance in rats. Br J Pharmacol 105:591-596.

Yokoo H, Yamada S, Yoshida M, Tanaka T, Mizoguchi K, Emoto H, Koga C, Ishii H, Ishikawa M, Kurasaki N, Matsui M, Tanaka M (1994) Effect of opioid peptides on dopamine release from nucleus accumbens after repeated treatment with methamphetamine. Eur J Pharmacol 256:335-338.

Zhou Y, Sun YH, Zhang ZW, Han JS (1993) Increased release of immunoreactive cholecystokinin octapeptide by morphine and potentiation of $\mu$-opioid analgesia by CCK-B receptor antagonist L-365,260 in rat spinal cord. Eur J Pharmacol 234:147-154. 